\title{
PREFACE FROM THE GUEST EDITORS
}

This Radiocarbon special double issue is dedicated to the "6th International Radiocarbon and Archaeology" Symposium that took place in Paphos, Cyprus - a real Mediterranean crossroads. The conference demonstrated that the inter- and intra-disciplinary nature of radiocarbon and archaeology research is no longer limited to an "exchange" of samples and dates, but is rapidly becoming an integrated whole, with the same student or researcher working in both worlds: radiocarbon and archaeology.

The four-day conference was attended by 142 participants from 28 countries. The participation was impressive with all participants present throughout the program. We had archaeologists, soil scientists, botanists, geologists, historians, mathematicians, and radiocarbon scientists contributing to an interesting and exciting meeting. The variety of subjects presented, both applications and methodology, covered the broad spectrum of topics where radiocarbon can have an impact on archaeology.

It is becoming more and more evident that to understand the past and to build an accurate and precise chronology of events, it is necessary to understand the context of radiocarbon samples in the archaeological record. The improvement of precision and accuracy of radiocarbon results is not only an analytical problem, but is the way to integrate many other events observed in the archaeological record on a real-time basis. This in turn requires the use of other methods, and in particular those that help define sample contexts that lie in the realm of microarchaeology.

This was the theme for this symposium: to reinforce the connection and dialogue between radiocarbon and archaeology in all the aspects of these fields. Comments and discussions after the sessions and the active participation in the poster presentations showed that the interaction between scholars in these fields is vibrant and innovative.

We would like to conclude by saying "THANK YOU" to all the participants since they made this meeting so informative and challenging.

Thanks also to the reviewers for their great work in providing suggestions and critical input to improve papers for these proceedings. Special thanks to Mark McClure and Prof. Tim Jull for their help in the preparation of these proceedings. We acknowledge our invited speakers, Prof. Pierre de Miroschedji and Prof. Marian Scott, for their enlightening presentations. Finally, we are grateful to the students and post-docs of the Kimmel Center for Archaeological Science of the Weizmann Institute for their help in organizing the conference from abroad.

Thanks to our sponsors: Municipality of Paphos, Cyprus Tourism Organization, National Electrostatics Corporation (NEC), and Kimmel Center for Archaeological Science for supporting the meeting; the Cyprus Institute for the website organization; and the Institute for Aegean Prehistory for helping support the proceedings publication. Special thanks to Sarah Hillel and Gail Tito from Target Conferences for their endless support during the conference preparation up until the last minute of the final dancing night! The pictures that follow show the incredible atmosphere during and after the meeting.

We hope to see you in Ghent 2013,

Elisabetta Boaretto and Noemi Rebollo Franco

Guest Editors 


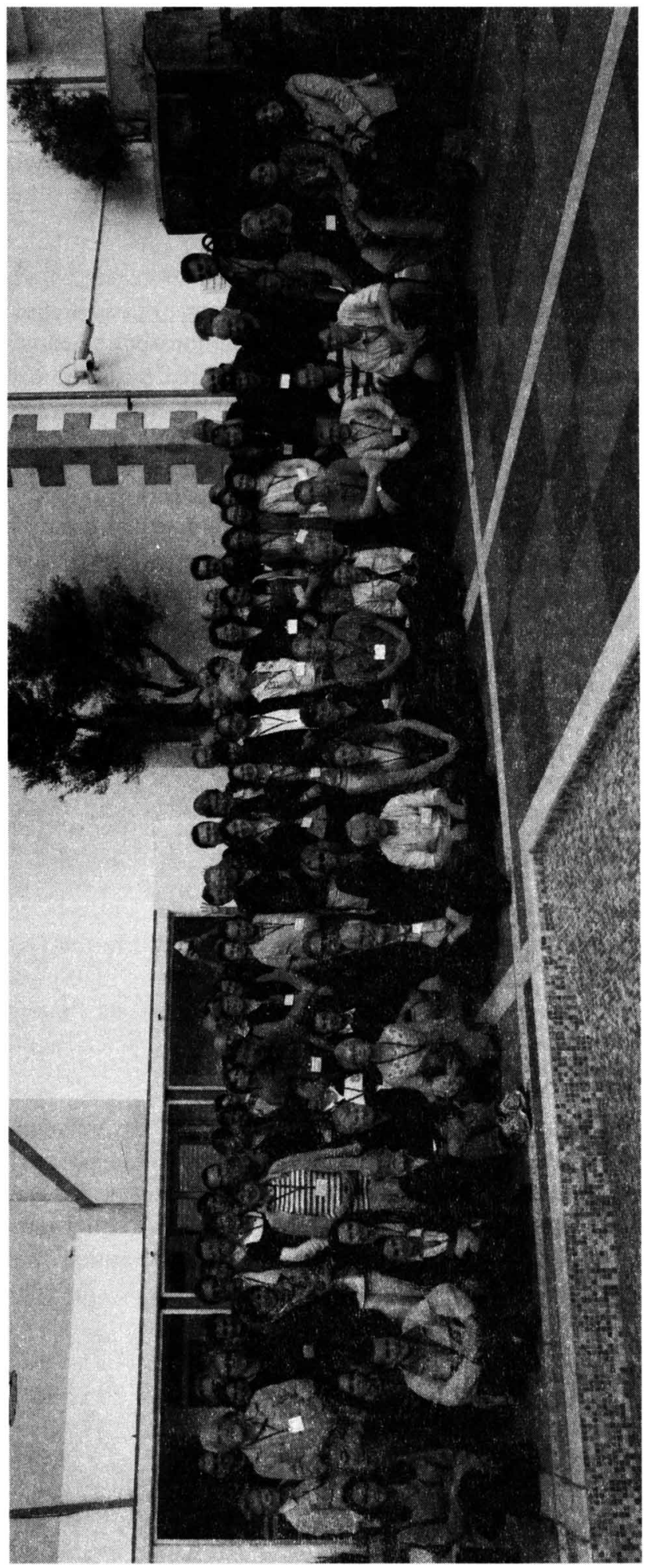



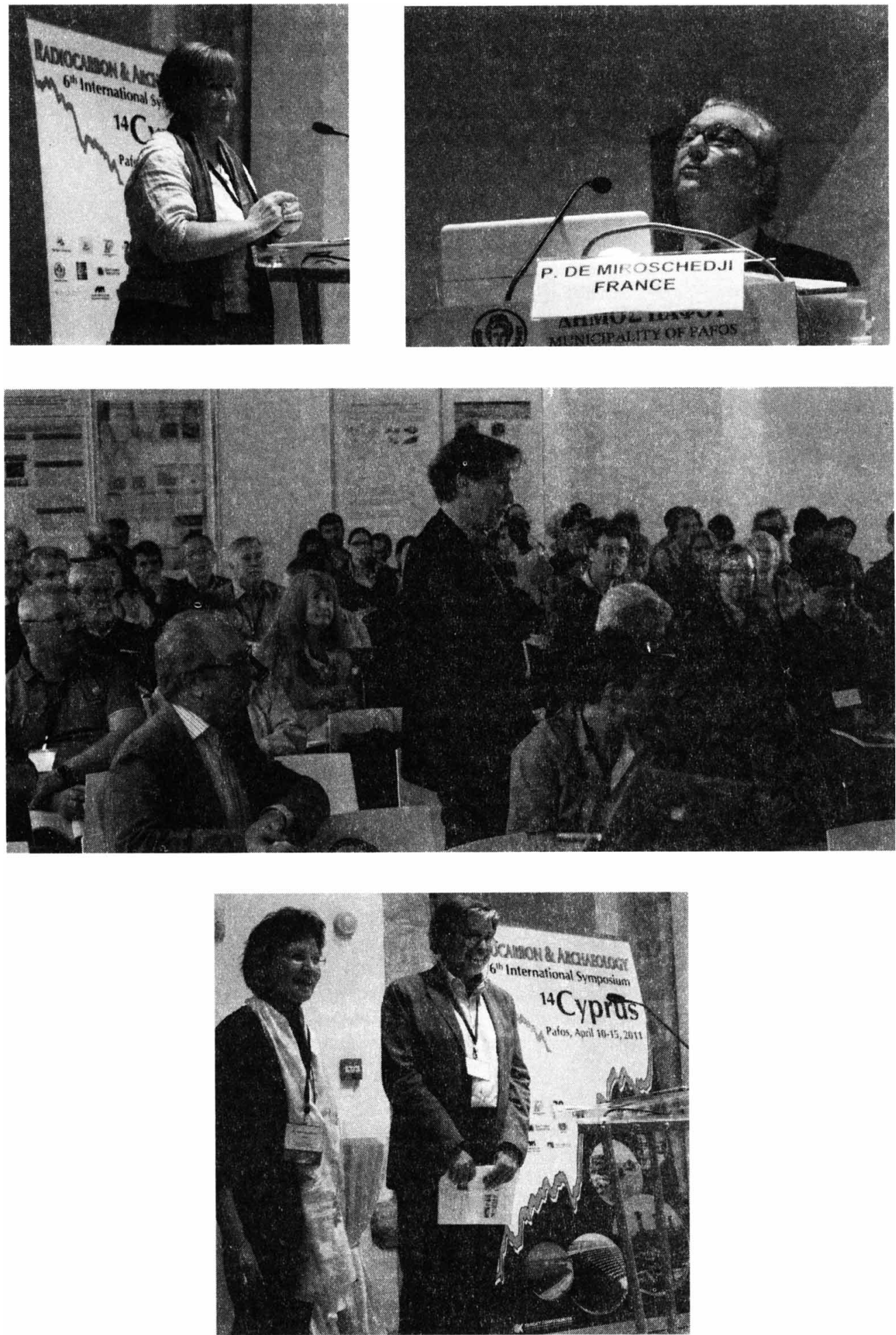

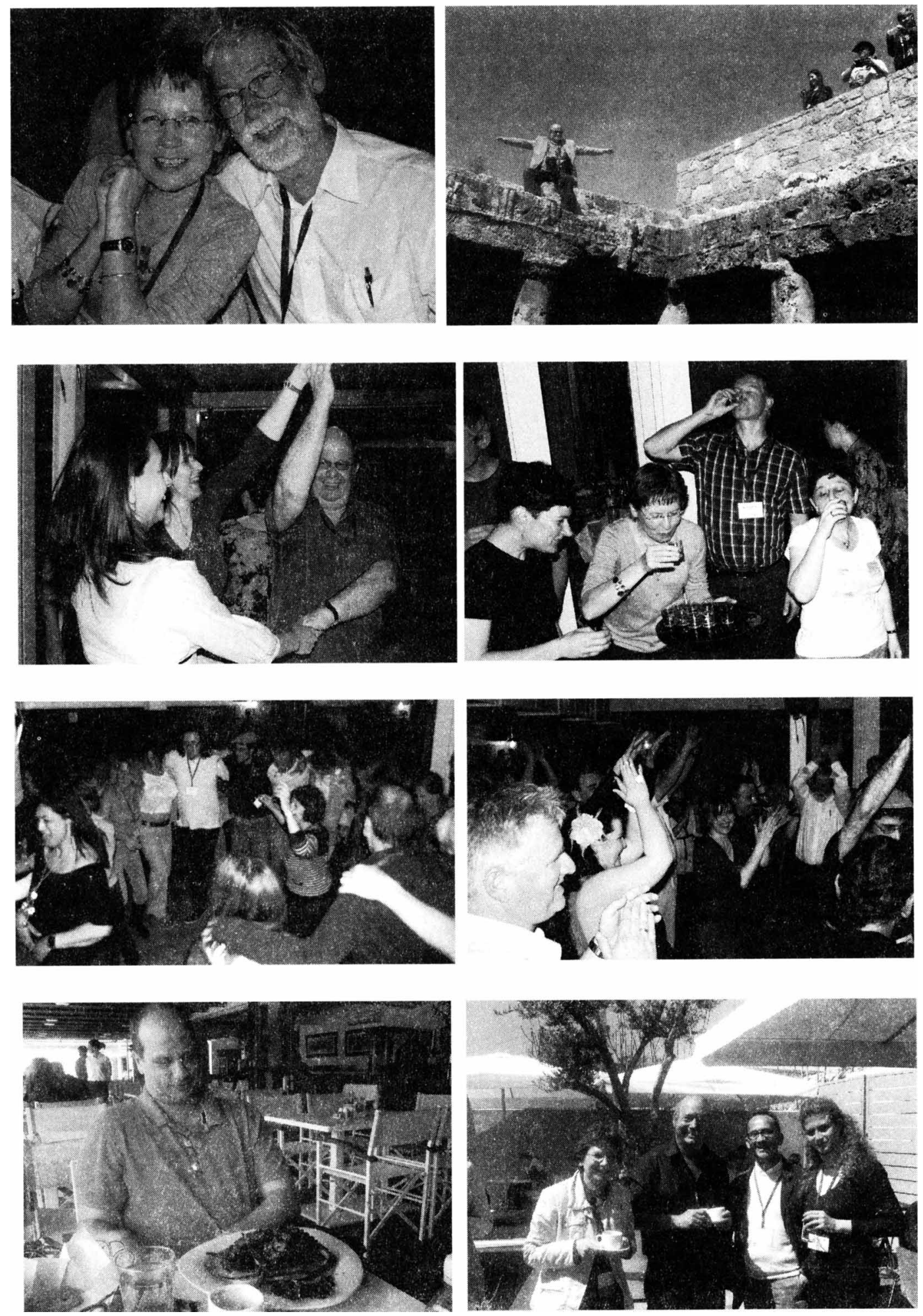